\title{
Pluralism, Pragmatism and Functional Explanations
}

\author{
Jamie Shaw \\ (University of Western Ontario) \\ jshaw222@uwo.ca
}

\begin{abstract}
While many philosophers speak of 'pluralism' within philosophy of biology, there has been little said about what such pluralism amounts to or what its underlying assumptions are. This has provoked some anxiety about whether pluralism is compatible with their commitment to naturalism (Cussins 1992). This paper surveys three prominent pluralist positions (Sandra Mitchell and Michael Dietrich's (2006) 'integrative pluralism', and both Peter Godfrey-Smith's (1993) and Beth Preston's (1998) pluralist analyses of functional explanations in evolutionary biology) and demonstrates how all three are committed to a form of pragmatism. This analysis both clarifies the justification and grounding of pluralism and allows these pluralisms to avoid the criticisms of Cussins. I close by making some more general points about pluralism and its relationship to history and integration.
\end{abstract}

Keywords pluralism; philosophy of biology; pragmatism; naturalism; functional explanations

DOI 10.1515/kjps-2016-0001

\section{Preamble}

The plurality of successful approaches in contemporary biology immediately raises the question about whether this plurality is simply inherent in studying complicated phenomena or whether these distinct approaches can or should be integrated into a single conceptual framework. In this paper I will address these larger concerns by considering two formulations of pluralism, that of Sandy Mitchell and Michael Dietrich (2006) 
and that of Peter Godfrey-Smith (1993) and Beth Preston (1998), and show how both implicitly commit themselves to a kind of pragmatism. Not only does making these commitments explicit clarify what kind of position pluralism is, but it also allows pluralists to withstand potential metaphysical and practical objections.

I begin this paper by briefly outlining some background on the literature on pluralism and then outline Adrian Cussins' (1992) arguments that any pluralist approach is inherently limited due to our commitment to naturalism. This will be followed by an outline of Mitchell and Dietrich's model as well as Godfrey-Smith and Preston's analysis of functional explanations. I then make explicit the pragmatist commitments of these positions and argue this position is perfectly compatible with Cussins' conception of naturalism. I close by considering both some potential objections and how a pragmatic form of pluralism can handle these considerations.

\section{Naturalism and Pluralism}

\subsection{Background on Pluralism}

There have been many forms of pluralism both within the philosophy of science (Suppes 1978; Dupré 1993; Cartwright 1999) and within philosophy of biology more specifically (Sterelny 1996; Fehr 2006; Waters 2006). The goal in this section is not to survey all of these positions, but provide a rough idea of some commitments generally agreed upon by most pluralists.

Pluralism begins with the observation that a plurality of models, methodologies, explanations or conceptual schemes exist within a given scientific domain. As a descriptive enterprise, this involves showing the various ways in which methods or explanations differ from each other. While certain disciplines at certain points in history will exhibit a greater or lesser amount of plurality, these pluralities seem to persist as a normal part of scientific practices. The question of what a general thesis of pluralism should be becomes complicated when we decide what implications this plurality has for more general philosophical considerations (e.g. what the goals of science are, whether there is a single correct method, whether there are universal laws in nature, etc.) This is where 
the contrast between pluralist and integrative or reductive approaches (and between different breeds of pluralism) becomes apparent. Some pluralists (Kellert et al. 2006) argue that the plurality of approaches in science is an essential feature of scientific practice while an integrative or reductive approach seeks to show how incommensurable approaches can be combined (either through assimilation or reducing one method to another). Other pluralists (Feyerabend 1975) will argue that such a plurality is normatively preferable since it is the most effective way to achieve scientific progress while some integrative accounts argue that the unity of science is the ideal of science (Carnap 1938). Thus, pluralists tend to endorse the normative position that some incompatibilities between certain features of science are not only tolerable, but desirable.

As we will see, the pluralists outlined in this paper share these commitments to providing normative view which encourages particular kinds of pluralities. Specifically, they argue we should be pluralists about explanations.

\subsection{Metaphysical Implications of Pluralism}

There has been some resistance to the claim that nature itself is somehow disunified. This disunification, some suggest, entails some kind of pluralism (cf. Cartwright 1994). Ross et al. phrase the worry like this: "with respect to the naive ontological disunity hypothesis...we are not convinced of its coherence. Is this thesis supposed to be that we inhabit multiple, separate universes at once? We don't understand this hypothesis if...it is intended as a variety of realism" (Ross et al. 2007, 194). ${ }^{1}$ Put another way, the worry seems to be that if we live in one unified reality, ideally, we should be able to have single unified explanation of it. Variants of the thesis of the unity of nature has quite the history and has been defended by many philosophers; Descartes unified all nature according to extension, Spinoza argued that nature (or God) must be unified in order to have infinite attributes, and Kant argued that nature is transcendentally unified due to the unity of the categories of understanding, and so on. Thus there is a historically prominent prima facie

$1 \quad$ It should be noted that the three positions outlined in this paper are all committed to realism. I will address this later in this section. 
objection that could be posed to any formulation of pluralism which posits multiple incompatible explanations of reality. To consider this objection more closely, let's look at the metaphysical criticisms of pluralism from Adrian Cussins.

Cussins argues that it is problematic to infer the claim that pluralism as a metascientific position is warranted from the plurality of explanations that exist within scientific practices. While Cussins does not provide a definition of pluralism, he seems to understand pluralism as the adopting of two positions: 1 ) we should be tolerant of incompatible explanations (i.e. explanations that postulate differing ontologies) and 2 ) that knowledge of explanations at one 'level' does not have any implications for knowledge at others (Cussins 1992, 180). In order for (1) to be plausible, (2) must be true or else pluralists would be committed to the absurd view that $A$ and $\sim A$ are both true. Put another way, in order for pluralism of explanations to tenable, there must exist multiple 'levels of discourse' (181).

The pluralist, according to Cussins, posits that each of these levels is autonomous and cannot be reduced to another level since there is no $a$ priori standpoint from which one can be said to be more fundamental (ibid). To illustrate this, Cussins provides an example of two explanatory levels: scientific and personal experiential. ${ }^{2}$ The former is constituted by cells, photons, nuclear fusion and so forth whereas the latter is constituted by tables, chairs, coffee, and so on. The pluralist does not want to privilege either level. The explanations of both are perfectly legitimate. When combined with realism, ${ }^{3}$ or the thesis that legitimate explanations are those which mirror reality, this commits the pluralist to the view that these explanations are equally true. Thus, in order for pluralism to be plausible, the metaphysics entailed by these commitments must be plausible as well. As will be seen in the following section, Cussins thinks

$2 \quad$ While Cussins focuses on the contrast between the 'scientific level' and the 'level of experience', his criticism also holds for any view that posits that there exist non-reducible levels.

3 Cussins assumes that pluralists also hold a realist thesis about explanations. Since the views discussed in this paper all presuppose realism (Mitchell and Godfrey-Smith are explicit in doing so (cf. Mitchell, 2004, 86; Godfrey-Smith 2003), this assumption does not affect the effectiveness of Cussins' argument. 
pluralism violates some basic naturalist assumptions and, thus, should be rejected.

\section{Limitations of Pluralism}

Since naturalism is a dominant view within philosophy of biology (and philosophy of science in general (cf. Giere 2006)), it would be deeply problematic for pluralism to violate its tenets. ${ }^{4}$ Cussins writes, "[f]or the thoroughgoing naturalist, rainstorms, amoebae, geological strata, galaxies, chairs, electrons, persons, minds, societies and God are all aspects of nature: parts of the one world" (188). All of these entities stand in certain causal relationships with each other and, thus, are interconnected. He cashes out this out with the notion of 'metaphysical tightness' or the idea that the behaviours of lower-level phenomena must be accounted for in explanations of higher-level phenomena. ${ }^{5}$ The pluralist, Cussins thinks, implicitly denies this thesis by positing the possibility of autonomous explanations. Thus pluralism requires that there be some sort of 'metaphysical gap' between levels. But this is clearly absurd: chairs are made up of molecules, humans are made up of cells, and so forth. The behaviour of these molecules and cells play at least some role in influencing the behaviour of middle-sized dry goods. Even if the whole is more than the sum of its parts, explaining the whole will still require an explanation of the parts.

As a result, for Cussins it is metaphysically incoherent to have multiple autonomous explanations which are each equally true. Instead, we must instead admit that explanations at different levels must somehow relate to each other. While Cussins does not develop this view fully, it remains an important objection that pluralists must be able to manage if they are to retain their pluralism and have an acceptable metaphysics.

\footnotetext{
$4 \quad$ Cussins' admits that some pluralists may hold dualistic tendencies, but these are problematic for well-known reasons (cf. Peacocke 1979).

5 Cussins does allow metaphysical room for supervenient or emergent relations to take place. Thus, explaining what a human is, say, may not be reducible to understand all of its constituent parts. However, any complete explanation of a human will require some reference to the behaviour of its constituent parts and thus explanations at these levels will still be complementary.
} 


\section{A Tale of Two Pluralisms}

None of the pluralist positions outlined in this section deny naturalism or the thesis that all of nature is interconnected. It is thus important to show how these positions do not succumb to the problems outlined in section 2.

\subsection{Integrative Pluralism}

Mitchell and Dietrich retains a form of pluralism despite admitting the interdependence of different areas of investigation. So while Cussins thinks naturalism precludes pluralism as a viable option, Mitchell and Dietrich adopt a pluralism which does not entail a bizarre metaphysics. Let us see how this works.

Mitchell and Dietrich's analysis begins from the downfall of panselectionism, or the thesis that "natural selection was the most important mechanism of evolutionary biology" (Mitchell and Dietrich 2006, 74) as the single approach to understanding evolutionary biology. This approach deemed that only adaptionist explanations are legitimate explanations of evolutionary phenomena. However, other approaches which emphasized phenomenon like random drift (Kondrashov 2005) and niche construction (Odling-Smee et al. 1996). Panselectionism, Mitchell and Dietrich argue, could only solve by "dismissing [them] as legitimate object[s] of explanation" (75). This is an unacceptable move since these research programmes, which demanded non-adaptionist explanations, were perfectly legitimate research programs. Furthermore, different 'levels' require different kinds of explanations. For example, evolutionary biology became divided into molecular and morphological levels when it became apparent that "[e]volution at the molecular level is marked by a significant role for random drift... [whereas], in contrast, evolution at the morphological level is marked by the predominance of natural selection" (74). Since random drift required more statistical explanations and morphological used more adaptionist explanations, the failure of panselectionism of providing a unified picture of all of these phenomena and at all levels meant there was a need for multiple kinds of explanations.

This is the grounding of pluralism for Mitchell and Dietrich: different levels and different phenomena require different kinds of explanations. However, like Cussins, Mitchell and Dietrich argue that these levels cannot 
be isolated from each other. They write, "[a]nswers to questions posed at different levels of analysis cannot be satisfactorily answered without consideration of the other levels" (77); these explanations may compete with each other. Take, for example, the impact evolutionary developmental biology had on traditional evolutionary biology. Even though 'evo-devo' was considered a distinct research field in the 1980s, the consequences of its findings had significant consequences for more traditional views of evolutionary biology (e.g. the ways in which developmental processes mediate the transitions between genotype and phenotype). ${ }^{6}$ Here, there are competing explanations which both seek to understand aspects of the same phenomenon (e.g. phenotypic changes during evolution) and the results from one research program puts constraints on the possible results on the other. ${ }^{7}$ This does not mean that either evo-devo or traditional evolutionary biological explanations will 'win' and become the single explanation, but that these two accounts must be integrated to understand the phenomenon. The 'levels of analysis' pluralism that Cussins rejects 8 "obscures rather than highlights the means of integration" (78), since it posits that explanations need not interact with those at other levels. On the other hand, "[i]n different particular cases, there will be different answers, but in any given case only one answer will map onto the actual processes" (77).

\subsection{Pluralism About Functional Explanations}

Peter Godfrey-Smith and Beth Preston provide two independent, but conceptually similar, investigations into the debate about functional explanations in biology. Specifically, they argue that instead of attempting to integrate two accounts of 'function', or argue for the supremacy of one over the other, we should retain both simultaneously. However, before outlining their pluralism, I will provide a bit of background on the debate about functional explanations.

There have been two explanations of function which are generally thought of as competing (i.e. incompatible) accounts of functional

$6 \quad$ I will not address the relationship between evo-devo and evolutionary biology in depth here. See Müller (2007) for a further discussion of this.

7 This picture is more fully developed in Mitchell (2002).

$8 \quad$ Mitchell and Dietrich associate this view with Sherman (1988). 
explanations: Larry Wright's 'historical' account and Robert Cummins' 'causal-role' account. This section will briefly recapitulate both of these positions.

Wright's analysis of function has two parts:

The function of $x$ is $Z$ means

a) $X$ is there because it does $Z$,

b) $Z$ is a consequence (or result) of $X$ 's being there (Wright 1973, 161). ${ }^{9}$

(a) is etiological; it claims that that $x$ 's existence is caused by what it does (i.e. what function it performs). The function of a heart is to pump blood because by pumping blood the heart continues to exist. Wright's analysis allows him to distinguish between the function of $x$ versus an accidental feature of $x$. For example, a heart pumps blood but it also makes a mild thumping sound. However, since the sound that a heart makes does not perpetuate its survival (i.e. account for it 'being there') it is not a part of its function. R.G. Millikan (1984) extends this account to include the historical lineage of a given organism. ${ }^{10}$ On Millikan's account, it is not enough that $x$ has a function which allows for its being there, but it also must have a history of previous generations of that organism having $x$ perform the same function. As she puts it, "every organ or system is associated with a set of functions that are biologically "proper" to it, functions that have helped account for the survival and proliferation of its ancestors" (Millikan 1984, 56). While this addendum restricts what counts as a function on Wright's account, the function/ accident distinction is drawn at the same place.

A second account of functions is Robert Cummins' 'causal-role' theory. Cummins argues that an explanation of $x$ 's function (i.e. a 'functional analysis') is the explanation of how $x$ 's causal capacities contribute to the system it's embedded in. The causal capacities of the system, on the other hand, are analysed in terms of the causal capacities of its parts.

$9 \quad$ There is an ambiguity here since 'being there' could be interpreted as being in a particular location, or why something is in existence at all. I will not address this interpretative difficulty here.

10 This was done to avoid counterexamples such as Boorse (1976). 
These parts can be treated as systems as well of even smaller parts. This analysis continues until the basic capacities are explanation sole by means of physical laws. To use Paul Griffith's example, while the functional explanation of an organism as a whole may be explain the mechanisms responsible for its survival and reproduction, this explanation can be broken down into explanations of simpler capacities such as mating, feeding, locomotion, escaping predation, and so on. Any one of these capacities can be broken down even further (e.g. feeding can be analysed in terms of the ability to ingest food, break down nutrients, and so on) until we arrive at basic capacities (e.g. that of a membrane to permit diffusion of some substance) which can be entirely explained in terms of physical laws (Griffiths 1993, 410-11). This differs from the historical account since Cummins' notion of 'function' implies an extremely liberal view of what counts as a function since almost all effects count as functions. ${ }^{11}$ This means Cummins' view includes no corresponding notion of 'malfunction', as opposed to Millikan's view, which does. Furthermore, contra Wright and Millikan, Cummins-functions are simply what effects they have now; the ability of an entity to perform a function has nothing to do with the history of that entity.

Whether Godfrey-Smith or Preston's analysis of this particular debate on functional explanations is correct is not my concern here. What I care about is the form of their arguments. Thus, I will not go into great detail about their arguments but tease out the aspects of their pluralism for my current purposes. Primarily, I will outline why Godfrey-Smith and Preston are pluralists about functional explanations.

Godfrey-Smith and Preston both argue that we should keep both explanations of function. Rather than attempting to integrate the two by reducing the two to some common base, or argue that one is importantly misguided in some sense, we should be pluralists and retain both explanations as independent accounts of function. Godfrey-Smith writes "[w]e should accept both senses of function, and keep them strictly distinct [since] [a]ll attempts to make one concept of function work equally for behavioural ecology and physiology are misguided" (Godfrey-Smith

11 See Preston (1998, 220-21) for a discussion of the limitations of what counts as a function. 
1993, 203). This is because we should not get too hung up on the fact that they both seek to explain something they label as a 'function', but instead recognize that both are addressing different questions (italics added, 208). This means we must accept that these are two different explanatory modes within science where each explanation can each be legitimately employed (205). Godfrey-Smith uses the example (borrowed from Kitcher 1993) of a particular mutant DNA sequence in the development of a tumour. Because the DNA sequence goes wrong in some sense, the cancer as a whole develops certain properties (207). The components of this system has both Wright-functions and Cummins-functions in this case; the Wright-functions of the stretch of DNA involved are the processes of cell division which keep the cell count at a certain level whereas the Cummins-functions (which are malfunctions for Wright) are the causal effects of the cancer-causing mutation. Thus both kinds of function must be explained to give a full account of the phenomena.

Godfrey-Smith then considers Kitcher's analysis seeks to unify Wright-functions and Cummins-functions under the notion of 'design.' He argues this account fails because it only recognizes the functions stemming from the design of the system (207-8). Kitcher's attempt obfuscates more than it clarifies since it refuses to recognize that both kinds of function are "two distinct explanatory models which are legitimate parts of our contemporary world view" (204). Without detailing how Godfrey-Smith comes to this conclusion, what is of current importance is that pluralism requires adopting both kinds of functional explanations since unifying them reduces our ability to fully explain some phenomena.

Preston's pluralism comes to the same conclusion as Godfrey-Smith: "both notions [i.e. functional explanations] are necessary [since] concerted attempts to do away with one of them fail" (Preston 1998, 216). However, instead of defending these two accounts from an attempted integration, Preston is criticizing Millikan's attempt to expand the historical account to explain ongoing exaptation (228). Here, Millikan attempts to expand her notion of a 'proper function' (i.e. "something specific [an entity] is supposed to do, even though they may never perform it" (215)) to include 'derived proper functions' which are new functions an entity gains in a new environment (232). Millikan uses the example of sea turtles flippers which were selected for the function of helping the 
turtle swim, but began to be used to dig holes. As Preston notes, a derived proper function is grounded on a "mere utilization relation" (ibid) whereas a proper function is grounded on its selective history. But the primary purpose of introducing the notion of selective history to explanations of function is provide a normative criteria for evaluating entities. This new expansion allows novel uses to count as functions as well which undermines the strength of Millikan's original position. It is important to note that by including phenomena that are not readily explainable, Millikan's attempt to expand the historical account leaves us with a shallow explanation. Its strength becomes undermined the more phenomena it attempts to explain. Rather, Preston argues we should be pluralists and allow other explanation schemes to enter which make better sense of phenomenon that the historical account cannot.

This is why Godfrey-Smith and Preston believe pluralism is warranted in the case of explanations of function: attempts to provide a single explanatory scheme undermine the strength of the historical or causal-role accounts in some sense. In Kitcher's case, it needlessly conflates kinds of function which results in a less adequate explanation. In Millikan's case, the historical account does not have the conceptual resources to account for all natural phenomena and thus fails to provide an adequate explanation for exaptions. The following section will offer an attempt to learn from this strategy, regardless of whether or not Godfrey-Smith or Preston's particular brands pluralism are successful, and see what implications this has for a more general form of pluralism.

\section{Pragmatist Assumptions of Pluralism}

Mitchell and Dietrich's integrative pluralism is pluralist because of the descriptive fact that there exist various kinds of pluralities in contemporary biology. Attempts to provide a single overarching framework have consistently failed to do justice to the value that each framework has on its own. Since some of these frameworks require different kinds of explanations, we can be pluralists both about the frameworks themselves and kinds of explanations. Godfrey-Smith and Preston's pluralism about functional explanations is focused on a smaller debate, but similarly conclude that having incompatible conceptions of function simultaneously 
is better than integrationist attempts. On the other hand, Godfrey-Smith and Preston seek to avoid integration whereas Mitchell and Dietrich welcome it. If Godfrey-Smith and Preston are correct in their interpretations, what are we to do about integration without being subject to Cussins' arguments from naturalism? I will argue that both forms of pluralism rest on pragmatic assumptions ${ }^{12}$ and that a recognition of this can make sense of both views on integration.

In response to a pluralist deriving pluralism from the fact that pluralities exist in science, an integrationist could equally point to instances of integration throughout the history of science to support integrationism. The integration of Mendelian genetics into Darwinian natural selection, for example, could be used to support the fact that integrationism is also a prominent feature of scientific practices. How can we avoid a stalemate between pluralism and integrationism here? Put another way, what is it about the fact that pluralities exist that warrants pluralism as a normative position about science?

Mitchell and Dietrich are only integrationists insofar as any explanatory scheme can be integrated (at least partially) with another since no explanation can be fully satisfactory if it is isolated from the other explanations which surround it. We should be open to such integration, according to Mitchell and Dietrich, because doing so would be detrimental to progress (such as in the case of traditional evolutionary biology learned from developmental biology). This means that insofar as integration is beneficial to progress, ${ }^{13}$ we should be integrationists. But Mitchell and Dietrich oppose other instances of integration, such as Richard Dawkins' attempt to integrate niche construction into traditional adaptationism. But in this instance, integration is not similarly valued since we lose something. ${ }^{14}$ Mitchell and Dietrich argue that "Dawkins... solves the problem of dealing with drift and neutrality only by dismissing it as a legitimate object of explanation. This strategy of narrowing the domain of evolution to include

12 I will not detail exactly which form of pragmatism (i.e. Jamesian, Peircian, etc.) these views are committed to and use the terms 'pragmatic' and 'pragmatism' quite generally.

13 I am not assuming the scientific progress is the only value one could hold here. I am open to the possibility that integration may be valued for other reasons as well.

14 More specifically, we lose the ability to use evolutionary mechanisms to explain molecular phenomena. 
only the processes and products of selection would certainly preserve panselectionism, but at the cost of disregarding a significant portion of molecular evolution" (emphasis added, Mitchell and Dietrich 2006, 75). This is what Godfrey-Smith and Preston's pluralist interpretations also rest on: Kitcher and Millikan's integrationist (or assimilationist) strategies are unwarranted not because integrationism is wrong per se, but because these particular integrations harm our explanatory abilities in some way (i.e. it needlessly obfuscates functional explanations or it is self-undermining). Thus we have pragmatic reasons to adopt integrations in some cases, but also to adopt pluralities in others.

So pluralism is warranted by virtue of its conduciveness to our interests. This makes pluralism a fundamentally pragmatist stance and not a universal stance about how science operates or ought to operate. In the next section, I will describe this position more fully by examining pluralism and integrationism against an extended timeline.

\section{Avoiding Naturalistic and Pragmatic Objections}

None of the positions outlined make their pragmatic dimensions explicit. However, there are advantages to conceiving of pluralism in a pragmatist fashion. This section will outline how a pragmatic form of pluralism avoids Cussins' concerns, and also avoids the potential objection that pluralism itself could be antithetical to progress.

As outlined in sections 1 and 2, Cussins argues that since entities and processes from various levels all interact with each other, explanations at any level must accommodate explanations from other levels. But these kinds of pluralism just mentioned are perfectly in keeping with this criteria; Mitchell and Dietrich's position allows for mutual constraints between explanations but is still pluralist since no single framework can explain all known phenomena. Furthermore, Godfrey-Smith and Preston's pluralisms are about kinds of explanations; the ontological commitments of both kinds of functional explanations are not mutually exclusive although what counts as a 'function' differs dramatically. What keeps us pluralists is our commitment to retaining multiple explanations or kinds of explanations instead of attempting to unify all explanations under a single heading. The pragmatic utility of doing this in no way conflicts 
with Cussins' conception of naturalism. However, even if Cussins' objection does not lead us to reject these formulations of pluralism, there is another objection which can be avoided by justifying pluralism on pragmatic grounds.

Both Mitchell and Dietrich and Godfrey-Smith and Preston's pluralisms operate within a particular timeline. That is to say, the inference of pluralism is made within a limited historical sample size. ${ }^{15}$ The larger historical question could be raised here: what reason do we have for presuppose that integration is not forthcoming? For Godfrey-Smith and Preston, simply because Kitcher or Millikan's attempts (or even every attempt thus far) to provide an integrationist ${ }^{16}$ picture has failed does not mean it is not possible in the long-run. Perhaps Kitcher's notion of 'design' could be suitably modified or some other notion could be conceived. The same question could be asked on a larger scale for Mitchell and Dietrich: why, in principle, can all scientific knowledge not be integrated into a single framework? Neither complexity nor historical divisions between different schools of thought seem to be enough here. Perhaps the panselectionist does find a way to integrate random drift and spandrels into their explanation; or maybe some future unforeseen explanation is able to integrate all approaches together without sacrificing any explanatory scope. Despite the fact that we may be skeptical that a complete picture of biology (or even science in general) may arrive (and even more skeptical that this is possible in the near future), there seems to be no strong reason to preclude the possibility of a single explanation for the natural world. ${ }^{17}$ Put another way, pluralism or integrationism on either micro or macro scales ${ }^{18}$ may fade given a longer historical time-

15 For Mitchell and Dietrich, this timeframe would be since the 1960s and Godfrey-Smith and Preston are looking at philosophical literature since Wright's article in 1973.

16 Although Preston accuses Millikan of offering an 'assimilationist' account, I am labeling in integrationist here insofar as a tries to integrate other phenomenon into its explanatory scope.

17 Mitchell and Dietrich could retain a form of pluralism even in this scenario since they argue that there can be pluralism within a single explanation. They illustrate this with the example of the plurality of causes involved in explaining the decline of amphibian populations (e.g. habitat destruction, climate change, increasing levels of ultraviolet radiation, etc.) (76).

18 I am using these terms loosely here to refer to individual issues and general fields of research here. 
frame. Thus, if pluralism does not embrace its pragmatic underpinnings, it will be forced to reject these future integrationist projects even if they were progressive. This makes pluralism without pragmatism unattractive and implausible.

If Mitchell and Dietrich, Godfrey-Smith or Preston were to reject that their pluralisms are pragmatically grounded they would require an additional argument as to why pluralism can always be held for their topic of interest. Since both forms of pluralism are inferred from snapshots of science, it is too strong of a generalization to suppose that 50 years of debates about the nature of evolution or 40 years of philosophical debate about explanations of function are indicative of the nature of scientific knowledge as a whole.

\section{Concluding Thoughts}

To sum up, I have argued that the pluralisms espoused by Mitchell and Dietrich, Godfrey-Smith and Preston must be conceived in pragmatist terms. Doing so allows pluralism to avoid the potential objections that pluralism is metaphysically problematic and that pluralism itself could be counterproductive for progress. This not only clarifies the nature of pluralism and its relationship to naturalism and integration, but also highlights the importance of pragmatism which has been gaining attention in the recent literature in philosophy of science (cf. Kitcher 2012).

Despite the fact that pluralists are often responding to over-zealous attempts to reduce or integrate the diversity that exists in scientific practices, they are over-zealous themselves at times. Indeed, claiming that pluralism is an irreducible fact of science is just this. There are many instances of pluralities of explanations working harmoniously with each other throughout history but there are also many instances of integration which exist as well. What is important is taking a close look at what individual instances of integration or pluralism offer in terms of our shared value of scientific progress. No pluralist should tear up if string theory turns out to be true and, similarly, no integrationist should let their methodological commitments interfere with a healthy and productive plurality. 


\section{Acknowledgements}

I'd like to thank Gillian Barker, Torin Doppelt, Tim Juvshik, and Jaclyn Lanthier for their invaluable contributions to this paper. I also greatly appreciate the comments and feedback from 3 anonymous reviewers which were instrumental for sharpening the arguments of this paper.

\section{References}

Boorse, C., 1976, Wright on Functions, Philosophical Review, 70-86.

Carnap, R., 1938, Logical Foundations of the Unity of Science, in International Encyclopaedia of Unified Science, 393-404, University of Chicago Press, Chicago.

Cartwright, N., 1994, Fundamentalism vs. the Patchwork of Laws, Proceedings of the Aristotelian Society, 279-92.

Cartwright, N., 1999, The Dappled World: A Study of the Boundaries of Science, Cambridge University Press, Cambridge.

Cussins, A., 1992, The Limitations of Pluralism, in D. C. Lennon, Reduction, Explanation and Realism, 179-223, Clarendon Press, Oxford.

Dietrich, M. \& Mitchell, S., 2006, Integration without Unification: An Argument for Pluralism in the Biological Sciences, The American Naturalist, S73-S79.

Dupré, J., 1993, The Disorder of Things, Harvard University Press, Cambridge.

Fehr, C., 2006, Explanations of the Evolution of Sex: A Plurality of Local Mechanisms, in S. Kellert, H. Longino, \& K. Waters, Scientific Pluralism, 167-190, University of Minnesota Press, Minneapolis.

Feyerabend, P., 1975, Against Method, Verso Books, London.

Giere, R., 2006, Modest Evolutionary Naturalism, Biological Theory, 52-60.

Godfrey-Smith, P., 1993, Functions: Consensus Without Unity, Pacific Philosophical Quarterly, 196-208.

Godfrey-Smith, P., 2003, Theory and Reality, University of Chicago Press, Chicago. 
Griffiths, P. E., 1993, Functional Analysis \& Proper Functions, British Journal for Philosophy of Science, 403-422.

Kellert et al., 2006, The Pluralist Stance, in S. Kellert, H. Longino, \& K. Waters, Scientific Pluralism, vii-xxviii, University of Minnesota Press, Minneapolis.

Kitcher, P., 1993, Function and Design, Midwest Studies in Philosophy, 379-397.

Kitcher, P., 2012, Preludes to Pragmatism: Towards a Reconstruction of Philosophy, Oxford University Press, Oxford.

Kondrashov, A., 2005, Evolutionary Biology: Fruitfly Genome is Not Junk, Nature, 1106.

Millikan, R. G., 1984, Language, Thought, and Other Biological Categories, MIT Press, Cambridge.

Mitchell, S., 2002, Integrative pluralism, Biology and Philosophy, 55-70.

Mitchell, S., 2004, Why Integrative Pluralism?, Emergence Publications, 81-91.

Müller, G., 2007, Evo-Devo: Extending the Evolutionary Synthesis, Nature Reviews, 1-7.

Odling-Smee, J. et al., 1996, Niche Construction, The American Naturalist, 641-648.

Peacocke, C., 1979, Holistic Explanation, Oxford University Press, Oxford.

Preston, B., 1998, Why is a Wing Like a Spoon? A Pluralist Theory of Function, Journal of Philosophy, 215-254.

Ross, D., Ladyman, J., Collier, J., 2007, Rainforest Realism and the Unity of Science, in Everything Must Go, 190-257, Oxford University Press, Oxford.

Sherman, P. W., 1998, The Levels of Analysis, Animal Behaviour, 616-619.

Sterelny, K., 1996, Explanatory Pluralism in Evolutionary Biology, Biololgy and Philosophy, 193-214.

Suppes, P., 1978, The Plurality of Science, Proceedings of the Biennial Meeting of the Philosophy of Science Association, 3-16. 
Waters, K., 2006, A Pluralist Interpretation of Gene-Centered Biology, in S. Kellert, H. Longino, \& K. Waters, Scientific Pluralism, 190-215, University of Minnesota Press, Minneapolis.

Wright, L., 1973, Functions, Philosophical Review, 139-68. 